\title{
UNIVERSIDADE, INOVAÇÃO E IMPACTO SOCIOECONÔMICO
}

\author{
Flavio Fava-de-Moraes \\ Professor do Instituto de Ciências Biomédicas da USP e Diretor Executivo da Fundação Seade. \\ Foi: Reitor da Universidade de São Palo, Secretário de Estado da Ciência, Tecnologia e Desenvolvimento Econômico e \\ Diretor Cientifico da Fapesp
}

\begin{abstract}
Resumo: O papel da universidade é inquestionável para a formação de pessoas qualificadas e para o desenvolvimento socioeconômico de um país, principalmente quando fundamentado em uma política científica tecnológica articulada no espaço das relações entre universidade, Estado, empresariado e outros setores sociais. Uma pesquisa sobre o MIT aponta nessa direção, ao demonstrar a importância da inovação e do fomento econômico propiciados pela atuação de seus alunos, professores e pesquisadores. Mérito acadêmico, ação estratégica para pesquisa, investimentos e transferência de conhecimento tornam-se referências para o alcance da mudança social e consolidação de uma sociedade. Considerações semelhantes podem ser admitidas notadamente para as Universidades Públicas do Estado de São Paulo.

Palavras-chave: universidade e sociedade; inovação tecnológica e desenvolvimento; impacto socioeconômico.
\end{abstract}

$\mathrm{M}$ uito se discute sobre o real significado da Universidade no papel posterior dos seus recémformados no desenvolvimento socioeconômico do país, estado ou cidade em que passam a atuar. Esta análise envolve muitos indicadores, tais como: integração a projetos de pesquisa inovadora em Universidades ou Institutos; participação em empresas modernas e competitivas; e criação de novas empresas de serviços ou tecnologias avançadas. Em qualquer dos casos, o objetivo é contribuir para mudanças tecnológicas, econômicas e sociais que afetem positivamente a riqueza nacional ou regional.

Importante estudo neste sentido foi recentemente concluído nos Estados Unidos, sob a coordenação e patrocínio do Banco de Boston, identificando a importância do Massachusetts Institute of Technology (MIT), através do seu alunado e das suas pesquisas inovadoras, na economia do Estado de Massachusetts, nos EUA e no exterior.

Se esta avaliação mostrou-se relevante naquele país, sua divulgação no Brasil é fundamental por constituir prova convincente do inquestionável papel socioeconômico que uma boa Universidade oferece para a sociedade e para a nação. Missão esta reconhecida por poucos e negada por muitos representantes dos poderes constituídos, que, por miopia, amiúde atacam a Universidade como centros elitistas, ociosos, privilegiados e descolados dos interesses das políticas governamentais e das demandas sociais.
Um dado inicial impressionante do MIT é a constatação de que as empresas criadas por seus alunos ou docentes egressos constituem, sozinhas, a 24 a economia mundial. São 4.000 empresas, com 1,1 milhão de empregados e US\$ 232 bilhões de faturamento anual (superior ao PIB de muitos países, como, por exemplo, a Tailândia). Portanto, é enorme o impacto que uma Universidade de Pesquisa (no caso, o MIT) gera nos mais variados aspectos da economia de uma nação.

A maioria destas empresas não é de grande porte, sendo que 1.500 foram criadas na década de 90 , com uma média anual de 150 empreendimentos novos e inovadores. Todas, além de possuírem profissionais qualificados, são preferencialmente de alta tecnologia aplicada a um limitado número de setores, como o da eletrônica, responsável por $13 \%$ das empresas, $57 \%$ dos empregos e $56 \%$ das vendas das 4.000 já citadas.

O MIT tem como missão atrair os estudantes mais talentosos do país (e do exterior), fornecendo com precisão o "estado da arte científico-tecnológico", estimulando-os precocemente no espírito empreendedor e no enfrentamento de riscos e gerando neles a confiança de que gente talentosa que trabalha em equipe vence desafios resolvendo problemas. É interessante destacar que apenas $8,7 \%$ dos estudantes do MIT são do Estado de Massachusetts e que muitos dos seus professores são estrangeiros, demonstrando que a Insti- 
tuição prioriza o mérito e desconsidera o corporativismo interno.

Esta identidade do MIT conquistou o reconhecimento social e a credibilidade tanto governamental como do setor privado, que lá investem, juntos e em quantias semelhantes, um total de quase meio bilhão de dólares em projetos de pesquisa. Dos investimentos privados que chegam a $30 \%$ do orçamento total do MIT, nada menos do que US\$ 70 milhões são destinados a 2.100 bolsas de pesquisa usufruídas por $40 \%$ dos seus estudantes. Estes devem, obrigatoriamente, participar como verdadeiros catalizadores dos projetos de pesquisa entre Universidade e empresa, pois sua alienação teria o risco de estas parcerias desvirtuarem integralmente a missão universitária.

Esta cultura institucional pela qualidade e pela inovação é o melhor mecanismo de transferência de conhecimento para as empresas criadas pelos formados no MIT, destacando-se o princípio de sempre respeitar o consumidor, ouvir empregados e fornecedores, fabricar produtos de excelente desempenho e reinvestir, em pesquisa, significativa parcela dos lucros (10\% a $18 \%)$. Este último ponto reflete a visão inteligente de que pesquisa e desenvolvimento são condições indispensáveis para a conquista e manutenção do êxito empresarial. Essa ação estratégica em pesquisa e desenvolvimento é visualizada concretamente nos EUA pelo aumento do investimento industrial privado que, de US\$ 97 bilhões em 1994, passou para US\$ 166 bilhões em 1999, com uma estimativa de US\$ 184 bilhões para o ano 2000. É interessante frisar que, nos EUA, os investimentos em pesquisa e desenvolvimento não são exclusivamente de origem nacional. Há bilhões de dólares de investimentos realizados por empresas estrangeiras, que até 1998 já estabeleceram 715 centros de pesquisa, sendo 505 deles oriundos principalmente de quatro países: Japão (251), Alemanha (107), Reino Unido (103) e França (44). As razões principais para estes países criarem Centros de Pesquisa e Desenvolvimento nos EUA têm sido, principalmente, o acesso aos cientistas e à infra-estrutura universitária e dos centros de inovação e a melhor cooperação interempresarial e a adequada comunicação com sua matriz sobre como adequarse ao mercado e ao meio de vida norte-americano. Ou seja, a relação Indústria/Universidade é entendida como de vital importância para o êxito empresarial e com benefícios mútuos via patentes compartilhadas, que cresceram de $8 \%$ (até 1973) para 25\% (até 1993), apesar de, com raríssimas exceções, o rendimento médio de licenciamentos para a Universidade (5\%) ser ainda muito baixo. Entretanto, se- ria absurdo encarar a relação custo/benefício dessa interação na Universidade sob o campo da lucratividade financeira sem considerar outras destacadas repercussões diretas e indiretas. A participação do financiamento empresarial na pesquisa universitária deve, contudo, merecer muita cautela para que não ocorra "sigilo e privatização (capitalização) do saber", o que seria um desastre total para os valores acadêmicos. $\mathrm{O}$ alerta se faz necessário porque já há muitos casos em que, para manter laboratórios e salários, pesquisadores comprometem-se a não publicar até mesmo resultados de pesquisa básica conveniada sem prévia autorização da empresa patrocinadora. Um exemplo marcante foi divulgado pelo Wall Street Journal (1996), quando uma empresa farmacêutica proibiu a publicação de pesquisa aceita por revista científica conceituada, ao saber que fármacos muito mais baratos de empresas concorrentes mostraram-se substitutos terapêuticos eficientes, fato que comprometeria o mercado da sua droga em US\$ 600 milhões anuais. Porém, cabe destacar que a pesquisa básica executada "espontaneamente" pela Universidade ainda é comprovadamente a maior fonte de resultados aplicáveis do que a pesquisa dita "encomendada” por empresa. O setor empresarial, sem dúvida, está mais diretamente interessado na pesquisa tecnológica inovadora, haja vista que só a IBM incorpora ao seu patrimônio, atualmente, mais de dez novas patentes por dia. Para tentar garantir tais objetivos, surgiram as chamadas "Universidades Corporativas", que, apesar dos resultados ainda inconclusivos, pretendem que o estudante receba um preparo mais específico aos interesses da organização.

Porém, mesmo com esses propósitos produtivos e com o Instituto de Pesquisa Industrial/DC/USA admitindo que $50 \%$ do PIB americano deve-se à inovação, o setor industrial não abandona o apoio à ciência básica (semente da inovação), pois seu financiamento, no período 1994-2000, passou de US\$ 6 bilhões para mais de US\$ 11 bilhões, dos quais US\$ 2,5 bilhões foram diretamente para as melhores Universidades. Esta ação estratégica, sem a qual a tecnologia torna-se obsoleta, ganhou ênfase prioritária no "Fundo de Pesquisa/Século 21", proposto pelo Governo ao Congresso Americano para, sob controle e avaliação da Fundação Nacional de Pesquisas, executarem no ano 2000 o maior investimento da sua história na valorização da ciência básica. No Brasil, a mesma prioridade está na Constituição Federal, art. 218, parágrafo 1ํㅡㄹ mas muito distante da realidade orçamentária! A exceção é o Estado de São Paulo que, sem cortar as fontes privadas, aportes 
federais ou recursos gerados por suas próprias instituições, aplicará em 2001, em ciência e tecnologia, um percentual do seu PIB compatível com o dos países mais desenvolvidos. Entretanto, uma iniciativa federal é a recente criação do Fundo Universidade-Empresa para a Inovação, lançada pela Lei no 10.168 , de 29/12/2000.

Voltando aos ex-alunos do MIT, é também preciso salientar que não há uma relação direta previsível entre o curso que realizam e a natureza dos seus empreendimentos posteriores: por exemplo, no setor de biotecnologia, $40 \%$ das empresas foram criadas por engenheiros e apenas $18 \%$ por biomédicos. Contudo, o setor industrial moderno, nacional e estrangeiro, tem crescido nos EUA prioritariamente nas áreas da tecnologia eletrônica e na biotecnologia, pois oito empresas destes dois setores estão entre as dez que mais investiram em pesquisa e desenvolvimento em 1998. Outro fator relevante é que o MIT, antes formador majoritariamente de engenheiros, gradua atualmente $43 \%$ dos seus alunos nas áreas de Ciências Sociais e Administração. Estes profissionais foram responsáveis pela iniciação de 892 empresas, em setores como Ciência Política (35), Urbanismo (89), Ciências Sociais (44), Filosofia (3), além de estarem sendo demandados cada vez mais para posições relevantes pelas empresas das "Ciências Exatas e da Vida". Isto quer dizer que uma boa Universidade nunca deve comprometer sua missão e seus valores e nem sujeitar seus esforços apenas com resultados de interesse mercantil e jamais deve ser julgada só pelo lado econômico, como fábrica de diplomas ou forja de produtos.

Consideração de relevância inquestionável sobre as empresas criadas pelos ex-alunos é a sua localização preferencial no entorno geográfico do MIT ou, quando em outras regiões, também próximas a Universidades qualificadas, demonstrando que a eficácia na inovação é tanto maior quanto menor é a distância do centro inovador.

Basta dizer que oriundas do MIT e localizadas na região metropolitana de Boston (Rota 128) estão 1.065 empresas, com 353.000 empregos diretos e US\$ 53 bilhões de faturamento (Digital, Gillette, etc.). Da mesma forma, também provenientes do MIT, mas situadas no Vale do Silício (Califórnia), estão outras 467 empresas, com 350.000 empregos e US\$ 86 bilhões em vendas (HewlettPackard, Intel, etc.).

Portanto, por inúmeras e óbvias razões, empresas dependentes da pesquisa e desenvolvimento associadas à inovação tecnológica não cometerão jamais a ingenuidade de interromper suas relações com excelentes Universi- dades de Pesquisa para cooperar, financiar e usufruir do avanço do conhecimento que terão "conseqüências" produtivas a médio e longo prazos. Ou seja, a Universidade ainda é o centro principal de produção do conhecimento em todo o mundo, embora não detenha mais a sua exclusividade.

Além disso, este "entorno universitário" apresenta outras vantagens que favorecem o crescente investimento empresarial: é fonte de pessoal talentoso e qualificado, está próximo de áreas procuradas pelo mercado consumidor; fornece boa infra-estrutura escolar, hospitalar, cultural, de telecomunicação, lazer, transporte, áreas verdes, etc., ou seja, constituiu-se em locais com diferenciais positivos para uma melhor qualidade de vida. Por isso tudo, é sabido que este desenvolvimento regional, que não é instantâneo, não ocorreria se o Estado não continuasse investindo com convicção num forte sistema universitário, no qual o MIT ocupa posição de inegável destaque. Ou seja, uma boa Universidade é requisito essencial, mas não totalmente suficiente para o desenvolvimento regional, pois seu êxito também depende das condições complementares de infra-estrutura e da capacidade de o meio externo absorver e utilizar o resultado de suas pesquisas.

Além destas citadas conseqüências internas para o Estado de Massachusetts e para os EUA, o MIT é também responsável por impactos além fronteiras, que lhe conferem prestígio internacional. Numa época de globalização, o êxito empresarial na conquista de mercados no exterior é critério de excelência no desempenho pela superação das dificuldades culturais, normativas e financeiras enfrentadas. Estes desafios estão sendo eficazmente vencidos, pois já são 220 as empresas estabelecidas por seus ex-alunos no exterior, predominantemente na Europa, mas destacando-se 52 empreendimentos na América Latina, sendo que o Brasil é o país mais procurado, com a instalação de 12 empresas.

Não é necessário argumentar laudatoriamente sobre a importância dessa questão estratégica e de se realizar estudo semelhante ao do MIT para comprovar que o Brasil também é dependente de suas boas Universidades. Não estamos ainda na vanguarda desejada e nem mesmo colhendo todos os frutos possíveis diante dos nossos esforços já realizados.

Entretanto, avançamos muito em curto espaço de tempo, pois nas Universidades Públicas do Estado de São Paulo, onde predomina a maior atividade científico-tecnológica brasileira (a pioneira USP só tem 66 anos), já temos exemplos de vários e inquestionáveis sucessos. 
Todavia, o Brasil não deve se iludir com importantes conquistas eventualmente exploradas com personalismo e ufania na mídia. O Brasil precisa conhecer o quadro real para ousar com humildade e exigir que decisões de política científico-tecnológica sejam tomadas conjuntamente pelas Universidades-Governo-Setor Privado (triângulo de Sabato ou tríplice hélice). Atualmente, outros setores sociais também devem participar da tomada de decisões. Finalmente, é fundamental que a Universidade concentre responsavelmente sua atenção na motivação de magnetizar a juventude talentosa neste árduo e contínuo desafio a vencer. Como mostrado neste caso do MIT, a Universidade é insubstituível não só na sua missão principal de educar gente capacitada para a futura liderança científico-tecnológica, cultural, política, empresarial, jurídica, diplomática, etc., como notadamente na formação dos cidadãos com riqueza de caráter que darão o grande diferencial na consolidação do sucesso almejado por nossa sociedade.

\section{NOTA}

Este artigo será publicado também no jornal Gazeta Mercantil.

\section{REFERÊNCIAS BIBLIOGRÁFICAS}

BRANSCOMB, L. M. "From technology politics to technology policy". Issues in Science and Technology. Spring, 1997.

BROWN, P. e SCASE, R. Higher education \& corporate realities. Londres, UCL Press, 1994.

BUSH, V. "Science: the endless frontier". A report to the president Roosevelt. Washington, US Gov. Print. Office, 1945.

BURGEN, A. Goals and purposes of higher education in the 21 st century. Londres, Jessica Kingsley Publ., 1996.

CLARK, B.R. Creating entrepeneurial universities. Oxford, IAU Press \& Pergamon, 1998.

CLINTON, B. "The government-university partenership in science". Issues on Science and Technology. Summer, 1999.

COLE, J.R.; BARBER, E.G. e GRAUBARD, S.R. The research university in a time of discontent. Baltimore, John Hopkins Univ. Press, 1994.

DERRY, G.N. What science is and how it works. Princeton Univ. Press, 1999.

ETZKOWITZ, H.; WEBSTER, A., GEBHARDT, C. e TERRA, B.R.C. "The future of the university and the university of the future: evolution of ivory tower to entrepreneurial paradigm". Research Policy, n.29, 2000, p.313-330.
FAVA-DE-MORAES, F. “Universidade-Indústria. Há um catalizador?” Rev. USP, n.25, 1995, p.16-19.

"Parceria Governo-Empresa estimula o avanço da ciência e tecnologia". Coleção CIEE, n.14, 1998, p.27-29.

. "Ciência, tecnologia e governabilidade: visão do poder Executivo". Cadernos de Gestão Tecnológica/Cyted, n.47, 2000, p.38-42.

. "Educación superior e desarrollo. Visiones del futuro. In: LOPEZSEGRERA, F. e FILMUS, D. America Latina 2020: scenarios, alternativas, estrategias. Buenos Aires, Temas Grupo Ed., 2000, p.257-264.

FLORIDA, R. "The role of the university: leveraging talent, not technology". Issues in Science and Technology. Summer, 1999.

GAUGER, J.D. “Entre Humboldt e 'high-tech': sistema e reforma do ensino superior na Alemanha”. Universidade: panorama e perspectivas. São Paulo, Cadernos Adenauer (n.6), 2000, p.83-104.

GODIN, B. e GINERAS, Y. "The place of universities in the system of knowledge production". Research Policy, n.29, 2000, p.273-278.

HIRSCH, W.Z. e WEBER, L.E. Challenges facing higher education at the millennium. Oxford, IAU Press \& Pergamon, 1999.

HORNBECK, D.W. e SALAMON, L.M. Human capital and America's future. Baltimore, John Hopkins Univ. Press, 1991.

KERR, C. "Society: industrial relations and university relations". The great transformation in higher education. (1960-1980). State Univ. N. York Press, 1991, p.181-196.

LARSON, C.F. "The boom in industry research". Issues in Science and Technology. Summer, 2000.

MIT: the impact of innovation. Bank Boston Economics Department Special Report, 1997.

MIYATA, Y. "An empirical analysis of innovative activity of universities in the United States". Technovation, n.20, 2000, p.413-425.

PURYEAR, J.M. e BRUNNER, J.J. Education, equity and economic competitiveness in the Americas. Interamer/OAS, 1994.

RHODES, R. Visions of technology. Nova York, Simon \& Schuster Inc., 1999.

ROSOVSKY, H. "The university as marketplace". The university: an owner's manual. Nova York, Norton Co., 1990, p.225-236.

ROSTRUP-NIELSEN, J.R. "Setting priorities in a new socio-economic context. An industrialist's views". Budapeste, World Science Conference/Unesco, June 1999.

SABATO, J. e BOTANA, N. "La ciencia y la tecnologia en el desarrollo futuro de America Latina”. Rev. Integr. Latinoamericana. Nov. 1968.

SANYAL, B.C. "Management of research and links with the economy". Innovations in university management. Paris, Unesco Publ., 1995, p.218252 .

SIBLEY, W.A. University manegement 2010. Challenging choices and difficult decisions. Stillwater, New Forum Press, 1998.

SILVA, A.C. "A regionalização do ensino e da pesquisa no Brasil". Universidade: panorama e perspectivas. São Paulo, Cadernos Adenauer (n.6), 2000, p. $45-57$.

SLAUGHTER, S. e LESLIE, L.L. Academic capitalism: politics, policies, and the entenpreneurial university. Baltimore, John Hopkins Univ. Press, 1997.

TENTI FANFANI, E. "Universidad y sector produtivo: del debate ideológico a la evolución de las experiencias". La universidad latinoamericana ante los nuevos escenarios de la región. México, Edit. Univ. Latinoamericana, 1995, p.421-434.

TRUNE, D.R. e GOSLIN, L.N. "University technology transfer programs: a profit/ loss analysis”. Tech. Forecast. Soc. Change, n.57, 1998, p.197-204. 